topics have been individually the subject of recent symposia and readers might find the information offered here rather sparse after referring to the reports of these specialized conferences. Finally, there are chapters on geography and ecology and their significance in taxonomic work.

I feel sure that students in particular will be glad to have this up to date information so efficiently brought together by Professor Heywood.

Brian Styles

\section{CAPTIVE ANIMALS}

International Zoo Yearbook

Vol. 9. Edited by Joseph Lucas, assisted by Ruth Biegler. Pp. viii $+336+24$ plates. ('The Zoological Society of London: London, Janıary 1969.) UK and Eire, 126s; overseas, $151 s$ 6 $d(\$ 18.75)$.

THus useful series of zoo yearbooks is aimed primarily at the zoo world, but it should be read and kept for reference by a much wider range of zoologists studying species in the wild and in captivity. Like its predecessors, this latest volume is interesting and entertaining to read, and full of facts. Many zoologists will find the reference section at the end particularly useful; this includes, for example, a census of rare animals living in captivity, and some of the themes of zoological research being done at zoos and aquaria all over the world. The reference section has also a special feature on studying wild animals in captivity.

Each ycar, the first section of the ycarbook is devoted to a special subject. In the past, these subjects have included the keeping of apes, ungulates and penguins in captivity. This year, the subject is the cold-blooded creatures, reptiles and amphibians. These animals are particularly difficult to look after because of their sensitivity to temperature. The section rightly starts with discussions on this aspect; then there are papers on subjects such as keeping arboreal and terrestrial amphibians in eaptivity, and the breeding of several species, for example, the Galapagos tortoise, the spectacled caiman, the rhinoceros iguana, and the bearded dragon (a type of

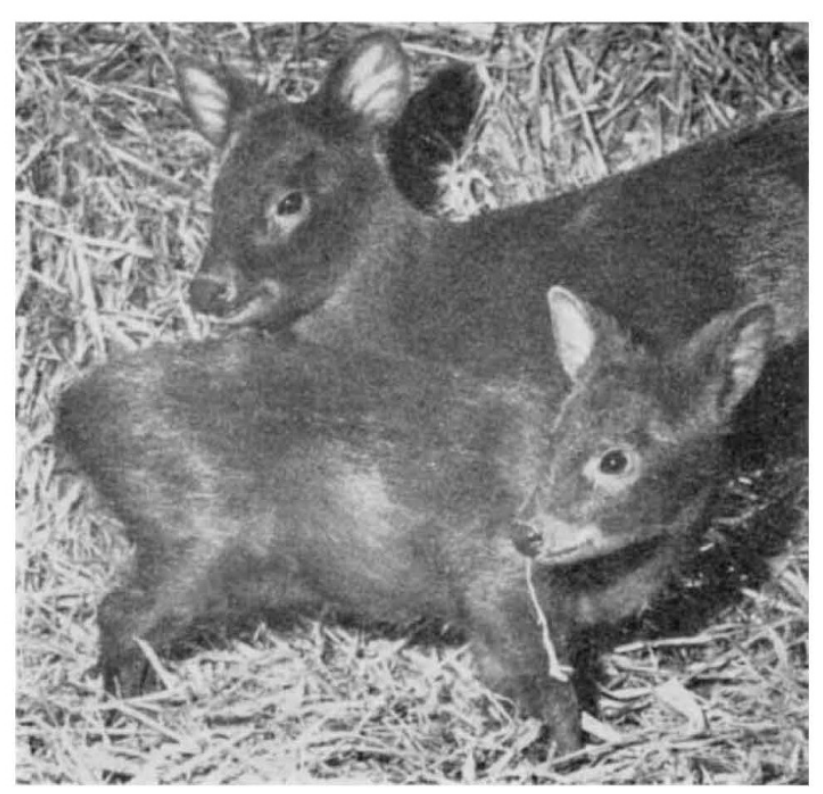

Male pudu (foreground) 52 days old and his mother in Cologne Zoo. (Plate 46, International Zoo Yearbook, Vol. 9. Photo by Uta Hick.) lizard). There is a delightful series of photographs on the hatching of the musk-turtle at Prague zoo, and of the hatching of the beauty snake at the University of Ibadan Zoo.

After reptiles and amphibians, the book passes on to the developments in the Zoo world-new architecture, breeding, conservation, education, husbandry and so on. Hand-rearing of aardvarks (ant-bears) is not a job keepers must do very often, but it happened in September 1967 at; Crandon Park Zoo in Florida when a female aardvark was born there. She was found to have been neglected by her mother and was fed with a bottle for about 14 weeks. Other breeding successes mentioned in the book include the rearing of a pudu (a rare dwarf deer from Chile) at Cologne $\mathrm{Zoo}$, and the breeding in captivity for the first time of a calf roan antelope at Hanover Zoo.

Zoos all over the world are becoming increasingly aware that they must no longer act only as custodians, but that they must conserve as well. If it had not been for the foresight of some zoos, a few endangered species would have probably become extinct. But while some of these animals can be kept out of harm's way fairly easily in zoos, successful breeding of them is more difficult, particularly if the pair has to be brought together from two different zoos. There have already been some successful matings of this sort (An-An and Chi-Chi excepted), and a further step towards more was made last year when a "marriage bureau" for zoo animals was established by a committee of the Federation of Zoological Gardens of Great Britain and Ireland. Another possibility would be to use a sperm bank as a tool for the preservation of rare animals. Professor $\mathbf{J}$. Mortelmas and W. Van den Bergh make a plea for this in the section on conservation.

This new yearbook is well produced and easy to read, and the publishers have maintained the high standard of its predecessors.

SARAH BUNNEY

\section{POLAROGRAPHIC EXPERIMENTS}

\section{Practical Polarography}

An Introduction for Chemistry Students. By J. Heyrovský and P. Zuman. Pp. viii +237 . (Academic Press: Londorr and New York, June 1968.) 50s.

IT is twenty years since the first German edition of Heyrovský's laboratory manual, P'olaragraphisches I'raktikum, appeared. Now, at last, we have an English transla. tion, taken from the second Czech edition which was written in collaboration with Dr Zuman.

The main part of this book consists of a collection of practical polarographic experiments based on the laboratory course which has been in use at Charles University in Prague for the past twenty years. These are very woll solected, and in a two-week course it should be possible to complete the majority of the experiments. The introduction covers the basic principles of the method, purposely excluding any theoretical discussion, and then goes on to discuss the types of electrode process and the interpretation of polarographic curves. The section on polarographic instrumentation contains some very useful hints on disturbances and their climination. Although the principles and operation of photographic recording polarographs are now largely only of historical interest, it might be pointed out that the polarograms reproduced throughout the book were made with a photographie recording instrument and have an acsthetic quality that the modern pen-recording polarographs cannot achieve.

Zuman has pointed out that one of the chief difficulties with the polarographic mothod is that, frequently, people with no prior experience of the technique turn to it for the solution of a difficult problem. Consequently, they have difficulty in carrying out the practical measurement or in the interpretation of the complex polarogram 